\title{
ENSEÑANZA DEL ESPAÑOL Y DIACRONÍA
}

\author{
Coloma Lleal Galceran \\ Universitat de Barcelona. Grup d'Història i Contacte de Llengües (GHCL) \\ colomalleal@ub.edu
}

\begin{abstract}
Resumen
En la enseñanza del español como lengua extranjera nos enfrentamos a menudo con temas difícilmente explicables a partir de una visión rigurosamente sincrónica. Sin embargo, muchas de estas cuestiones pueden ilustrarse recurriendo a los datos que nos proporciona la diacronía.

Me centraré en este artículo en el análisis de cuatro temas controvertidos: los usos del artículo, las relaciones entre los verbos copulativos ser y estar, las características de los clíticos (con los fenómenos de leismo, laismo y loísmo), y los cruces entre las preposiciones por y para.

PALABRAS CLAVE: lingüística diacrónica, ELE/L2, artículo, clíticos, preposición.
\end{abstract}

\begin{abstract}
When we try to teach Spanish as a foreign language, we often face to some issues that are difficult to explain with a synchronic point of view. However, the majority of these issues can be illustrated using the data provided by diachronic linguistics.

In this article, I will focus on the analysis of four controversial issues: use of article, relation between copulative verbs ser and estar, properties of clitics (with leismo, laismo and loismo phenomena), and the crosses between por and para prepositions.
\end{abstract}

KEYWORDS: diachronic linguistics, ELE/L2, article, clitics, preposition.

\section{Presentación}

Cuando en la enseñanza de español para extranjeros intentamos explicar algunos temas de nuestra gramática a partir de planteamientos rigurosamente sincrónicos, nos vemos a menudo obligados a recurrir a argumentos ad hoc, a inventarnos curiosas reglas plagadas de excepciones o, lo que a mi juicio es más grave, a falsear los datos en aras de una explicación aparentemente más clara. No se trata de atosigar innecesariamente a nuestros alumnos con unos métodos de análisis que no corresponden a sus necesidades comunicativas. Pero el profesor ha de conocer las líneas generales de la evolución para, a continuación, intentar encontrar la manera de exponer sucintamente el porqué de algunas aparentes anomalías.

A título de ejemplo, analizaré cuatro temas controvertidos del español que presentan dificultades de aprendizaje a alumnos procedentes de otras lenguas: las formas, valores y usos del artículo, las relaciones entre los verbos copulativos ser y estar, las características de los clíticos (con los fenómenos de leismo, laismo y loismo), y las concomitancias entre las preposiciones por y para. En todos ellos, los datos que nos proporciona la diacronía, y también la referencia a las soluciones adoptadas por otras lenguas, nos permiten alcanzar explicaciones coherentes con la realidad de los hechos. 


\section{El artículo}

\subsection{Orígenes del artículo en las lenguas románicas}

Es conocido que el latín carecía de esta categoría gramatical que, sin embargo, aparece en todas les lenguas románicas (como palabra dependiente que precede al nombre-caso del español, del catalán, del portugués, del francés, del italiano...- o bien como forma enclítica del nombre -caso del rumano-). Las formas del artículo derivan de lo que había sido en latín un demostrativo (generalmente ILLE y, en algunas áreas, IPSE).

El desarrollo de esta nueva categoria responde, fundamentalmente, a factores internos del propio latín, en los que incidieron, además, algunos factores socioculturales.

Recordemos que el latín era una lengua flexiva que, al igual que el resto de lenguas indoeuropeas, expresaba mediante morfemas gramaticales las nociones de caso:
(1) magistri filia magum amabat fliae magister magum amabat magus magistri filiam amabat magus fliae magistrum amabat
('la hija del maestro amaba a un mago') ('el maestro de la hija amaba a un mago') ('el mago amaba a la hija del maestro') ('el mago amaba al maestro de la hija')

Pero, en una tendencia general que ha afectado, en mayor o menor medida, a todas las lenguas indoeuropeas, ya desde tiempos del Imperio se observan frecuentes confusiones que culminaron con el uso de una forma única, derivada de lo que había sido la del acusativo. El valor sintáctico de esta forma única uśada como genitivo (o complemento nominal), dativo (u objeto indirecto), y ablativo (o complento circunstancial) se pasó a expresar mediante el uso de una preposición. Pero la función de objeto directo no admitía el uso de preposición, con lo que las funciones de sujeto y de objeto directo habrian quedado indiferenciadas, con las consiguientes ambigüedades y confusiones que ello implicaría ${ }^{1}$. Así, se hizo cada vez más frecuente el uso de un demostrativo ante la unidad nominal en función de sujeto, situación que suele darse junto a una tendencia a reordenar los elementos de la frase según el esquema SVO:

\section{(2) illa filia de magistru magu amat $>$ illa filia de magistru amat magu illu magistru de filia magu amat > illu magistru de filia amat magu illu magu filia de magistru amat > illu magu amat filia de magistru illu magu magistru de filia amat > illu magu amat magistru de filia}

Esta situación se vio, además, favorecida por la difusión del cristianismo y la aparición de las primeras versiones de la Biblia al latín a partir de un original griego, lengua que sí tenía artículo, de manera que los traductores, en su afán de fidelidad a un texto sagrado, traducían sistemáticamente el artículo griego por aquello que, en su lengua, era más próximo, es decir, por un demostrativo ${ }^{2}$.

1 En algunas áreas de la Romania (como en la Galorromania) se mantuvo durante algunos siglos una clara distinción entre una forma para la función de sujeto y otra para la de cualquier complemento, pero no fue este el caso del área donde se desarrollaría el castellano, donde no hay indicios de esta diferenciación bicasual (caso sujeto vs caso régimen).

2 Es conocida la relación existente entre demostrativos y artículos: en las lenguas que poseen artículos, estos suelen proceder de antiguas formas de demostrativos (piènsese en el inglés this, that, the). 


\subsection{El artículo en el castellano medieval: formas y usos}

\subsubsection{Primeras manifestaciones del artículo}

Sigamos ahora, brevemente, los primeros pasos del artículo en castellano. Cuando, a partir del siglo $\mathrm{x}$, empezamos a encontrar documentación en romance primitivo, observamos que se ha producido un fenómeno significativo: la extensión del uso del artículo a las otras funciones sintácticas y no solo ante el sujeto ( $\mathrm{y}$, por lo tanto, también tras preposición), con lo que el artículo ya no es la marca de la función, sino que ha adquirido un nuevo valor como identificador:

(3) In illo pozo de illa sale et solares populatos et per populare (978)

in ila vinia majore, .ii.; .ii. ad ila tore; .iiii. quespiseron quando ilo rege uenit. (Noditia de kesos, León, 980).

et illa terra de la fikera et illa uinea de la forka pernominata (1078)

et dono tibi in Boleia illos casales quod michi petisti intro illo muro, prope illa lacuna de illa porta usque ad illo orto, sicut se tenent in costa de illo muro (1104)

Este nuevo valor como identificador, con referencia, implícita o explícita, a algo conocido por emisor y receptor, supuso la necesidad de disponer de una nueva forma, de función similar a la del artículo, pero sin ese valor de identificador. El numeral uno vino a llenar este vacío, usado primero como pronombre indefinido $y$, de ahí, como artículo indefinido:

(4) et dono tibi in Barbastro unas casas cum tota illa hereditate (1101) Et dono tibi unos casales, siue ereditate, ubi te facias cavallarizas (1102)

et una vinea in capud de orta de Montson; et unas casas in villa Montson; et unas casas in civitate de Barbastro; et uno orto de intus illo muro (1102)

et un lijar de lino et otro destopa et un manto corderuno pora los domingos (Fueros de la Novenera, 1150)

Con ello, tenemos ya anunciados los dos artículos del castellano. Veamos, a continuación, la evolución que siguieron estas formas y sus usos.

\subsubsection{Origen de la forma el del artículo femenino}

Las formas del latín (ILLUM - ILLAM - ILlos - ILLAS), como consecuencia de los cambios fonéticos del latín al castellano, presentaban inicialmente las formas elo, ela, elos, elas:

(5) elo terzero diabolo uenot... elos serbicios... ela legem... qual duenno tienet ela mandatione... ke denante ela sua face... (Glosas Emilianenses. s. XI?)

Formas que, por su carácter átono, a partir del siglo xII, tendieron a reducirse: elo $>\mathrm{el}$, ela $>$ la, elos $>$ los y elas $>$ las. Sin embargo, se observan algunas alternancias entre el/la, generalmente en relación con la fonética sintáctica, de manera que ante vocal (inicialmente 
ante cualquier vocal) deja de ser perceptible el último sonido vocálico del artículo, mientras que en contextos consonánticos el menos perceptible es el primero de los sonidos vocálicos del artículo:
(6) el(a) uva > el uva
pero
(e) la casa > la casa
ella) onza $>$ el onza
pero
(e)la puerta $>$ la puerta
el(a) escalera $>$ el escalera
pero
(e) la tapia > la tapia
el(a) acequia $>$ el acequia
pero
(e)la mesa > la mesa

En textos primitivos, se produce una situación similar con las formas del masculino, con alternancias entre $e l$ y lo, que, después del siglo XII, tras la consolidación de la norma alfonsí, solo perviven como rasgos dialectales. Las alternancias de las formas del femenino (el/la), en cambio, llegan hasta nuestros días. Pero no se dan ya ante cualquier vocal. A partir de mediados del siglo xiII solo las encontramos ante [a-] (tanto tónica como átona) y, esporádicamente, ante [e-]:

(7) de venjda del aldea ala villa (1196) del una part la carrera. del otra parte solar de Diago Gonzalez (1222) en cabo del escalera fallaron una posada (Conde Lucanor, 1330-35) Arteria. por el arteria o vena de aire (Nebrija, Dictionarium, 1492).

\subsection{El artículo en el español moderno y contemporáneo}

\subsubsection{Restricción vs. ampliación de los usos del artículo femenino el}

Por una parte, el uso moderno ha restringido aún más los contextos fónicos en que se produce la apócope, ya que sólo se da ante sustantivo que empieza con [á-], pero simultáneamente, se ha extendido analógicamente al artículo indefinido un:

(8) Podia verse a lo lejos el agua clara (R. Regás Azul, 1994)

Se internaron en un agua muy mansa (L.A. de Villena, El burdel de Lord Byron, 1995)

La tendencia analógica de los hablantes, fomentada por la explicación a menudo simplista de sus profesores que se refieren a estos casos como de un "artículo masculino", conduce a menudo a una extensión sistemática de este uso por reanálisis, que afecta incluso a las concordancias, y da lugar a construcciones del tipo:

(9) *este agua, * $\underline{\text { mucho hambre, **un águila majestuoso }}$

Bastaría con decir que el primitivo artículo femenino ela ha evolucionado normalmente a la, pero que ha dado $e l$ ante vocal tónica, para evitar barbarismos (o barbaridades) de este estilo. Que dos formas acaben coincidiendo no significa que se trate de la misma forma: es el conocido fenómeno de homofonía. No creo que a nadie, para simplificar, le convenza la explicación de que para nombrar el 'zumo fermentado de la vid' usamos la forma de pasado del verbo venir. Pero muchos siguen explicando el uso de el agua con un argumento equivalente. 


\subsubsection{Ampliación de usos del artículo}

Por otra parte, se ha dado modernamente una ampliación de usos del artículo. Recordemos que, como consecuencia de su valor como identificador, el castellano medieval no solía usar el artículo ante nombres que, por su contenido semántico, eran suficientemente identificados. Este es el caso de los nombres de objeto único:

(10) Nos don Joan uendemos ... las casas e las tiendas e los huertos e la nuestra uinna de Tafaia con entradas exidas e con quanto derecho nos y auemos desde cielo fasta tierra. (1228).

jazje dentro en infierno con Judas abraçado (Alexandre, 1240-50)

En tal manera recibio muerte por nos sacar de infierno. e dar nos el bien de parayso. (Primera Partida, 1256)

non es tierra en mundo que aya tales pasturas (Fernán González, 1250)

E la uez que ouo sobre mar la guerra en Marsiella. (1270)

Algo parecido ocurre con los términos de objetos genéricos:

(11) non ha cabero d'armas en el mundo mejor. (Fernán González, 1250)

por querella que ovieren navarros de castellanos o castellanos de navarros que gelo non consintamos (1293)

Pero a partir de siglo XIv empieza a extenderse el uso del artículo en estos contextos:

(12) asi como en el infierno las almas de los malos (Libro del cavallero Zifar, 1305) que si los castellanos entravan que acorran e ayuden e los nuestros (1301)

o con los nombres de los días de la semana, donde desde antiguo alterna la presencia y la ausencia de determinante:

(13) el domjngo de venjda del aldea ala villa, e el martes de tornada al aldea; (1196) Ffecha la carta en Sant Millan, martes primer dia de julio (1270)

Del dia de Ramos asta martes depues de Pasquiela, non den fiel (1300)

o bien después del cuantificador todos con nombre contable:

(14) e priso Samaria, e leuo todos los omnes de la tierra catiuos a Siria. (Liber Regum, 1194)

Quoales personas deuen ser en todos iuyzios de Rey ... Et demas porque los cabeçaleros non sean todos dias embargados e puedan complir (Fuero de Navarra, 1330)

En todos estos casos, observamos que el español ha ido ampliando el uso del determinante, hasta hacerlo obligatorio en español actual. Con ello, se ha apartado del uso que se da en otras lenguas, que conservan un uso próximo al que encontrábamos en castellano medieval (caso del inglés, por ejemplo). 


\subsubsection{Valores partitivos del articulo}

Otro cambio importante entre los usos antiguos y los modernos afecta a los valores partitivos. El castellano medieval solía construir el nombre usado con valor partitivo con artículo precedido de la preposición de:

(15) e assi coma del pan e beua del caliz (1270)

porque coma con el e beua del uino en grand alegria (1280)

como podamos fazer que este non coma del pan e que nos solos lo comamos (Libro de los exemplos, 1400)

da al paçiente a comer vna onça cadal dia e beua del vino en que fue cocha Recetario, 1471).

Pero a partir de 1500 , es muy raro encontrar esta estructura de prep. + det. ante el nombre partitivo:

(16) e todos estos diez annos nin coma carne nin beva vino, salvo las fiestas (1500).

Con ello, el español se aparta de otras lenguas románicas que, como es el caso del francés, conservan este uso. Obsérvese, sin embargo, que con la desaparición del artículo con valor partitivo se anuncia una nueva estructura que llega hasta nuestros días y que parte de la diferenciación entre nombre contable (con artículo definido o indefinido) frente a nombre usado con valor partitivó (sin artículo):

(17) tener un disgusto / producir disgusto oir un ruido / hacer ruido. comer el pan de ayer / comer pan.

\subsubsection{Función nominalizadora del articulo}

Un último valor, muy productivo en español, es el que marca la función nominalizadora del artículo definido, función que encontramos ya en textos medievales y que se conserva en la actualidad, con la especialización de la forma neutra lo como nominalizadora de adjetivos, y de la forma el como nominalizadora de verbos:

(18) por mayor derecho tiene el eglesia de toller les el comer, que de gelo dar (1256) porque ayades entendimiento e saber entre lo bueno e lo malo, e lo santo e lo descómulgado (1275)

el plazo passado, deuen les uedar el comer et el beuer fasta que mueran de fanbre (1300)

alegraron se mucho por aquello e loaron mucho el cantar del iuglar (1385)

en el andar es perezoso. y en el trabajar flaco (1500)

Dios suele ... allanar lo terrible, y hacer lo imposible ser posible (1617)

pues tú le diste lo mejor que tenias; y tu padre no dio otra cosa (1786)

el saber no ocupa lugar. Lo cortés no quita lo valiente. 


\section{Los verbos ser y estar}

\subsection{Orígenes latinos}

Una vez más, nos remontaremos a los orígenes latinos de estos verbos para intentar establecer la evolución de sus usos hasta el español contemporáneo.

Recuérdese que en latín el verbo Esse tenía un uso copulativo, un valor existencial, un valor intransitivo y valores auxiliares en perífrasis de pasiva para los tiempos del perfectum. El verbo staRE, en cambio, era un verbo intransitivo con el valor de 'estar de pie'.

En los primeros textos romances observamos que, por una parte, como consecuencia de los cambios fonéticos, algunos tiempos del verbo esse dejaron de utilizarse y, en su lugar, pasaron a usarse las correspondientes formas del verbo SEDERE 'estar sentado':

(19) In uestro jure de uobis Petru Flainiz et de uxor uestra Bronildi sedeant confirmatus (1009) uenga a la uilla. et prenda fidiador per foro de la uilla. et sedea solta illa pindra. (Fuero de Avilés, 1155)

Por otra, vemos que en algunas lenguas románicas, ESSE y STARE acabaron confluyendo en un verbo único (caso del francés, por ejemplo, donde algunos tiempos derivan de ESSE y otros de STARE: estre > être, j'étais, etc.). En castellano, en cambio, se mantuvieron los dos verbos, pero sus usos se entrecruzaban a menudo.

\subsection{Copulativos, auxiliares y perífrasis de pasiva en español medieval}

\subsubsection{Valores del verbo ser}

Los principales valores del verbo ser en castellano medieval derivan directamente de los usos latinos:

\subsubsection{Valor copulativo}

(20) E dixieron. non sennor mas tos sieruos somos. todos fijos de un omne leal e non somos barruntes. (Fazienda de Ultramar, 1200)

La terçera razon por que dezimos que es mas alta, es por que de todas las ordenes que Dios fizo es la mas alta caualleria (Libro de la Monteria, 1345-50)

3.2.1.2. Valor existencial, equivalente a 'existir'

(21) Sepan los qui agora son e los que an a seer cuemo io Gonzaluo Pedrez uendo (Grijalba, 1222) non es tierra en mundo que aya tales pasturas (Fernán González, 1250) todas las cosas an tiempo e por sus espacios e medidas passan quantas cosas so el sol son. (General Estoria) que mas leal trotera nunca fue en su memoria (Libro de Buen Amor, 1330-43) Nos tenemos que entre todas las caças que pueden ser, que la caça delos uenados que es la mas noble (Libro de la Montería, 1345-50) 


\subsubsection{Perifrasis de pasiva}

El latín clásico expresaba la voz pasiva con desinencias en los tiempos del infectum y con perifrasis con ESSE, en los del perfectum. Pero los hablantes tendieron a generalizar las construcciones perifrásticas para todos los tiempos, usando las que habían sido formas del perfectum para el infectum, y creando nuevas formas analógicas para el infectum. Las antiguas formas de pasiva sintética, mediante desinencias, no han llegado a ninguna lengua románica:

\begin{tabular}{|c|c|c|c|c|}
\hline infectum & perfectum & & infectum & perfectum \\
\hline $\begin{array}{l}\text { amabar } \\
\text { ('era amado') }\end{array}$ & $\begin{array}{l}\text { amatus eram } \\
\text { ('habia sido amado') }\end{array}$ & $\leftrightarrow$ & $\begin{array}{l}\text { amatus eram } \\
\text { ('era amado') }\end{array}$ & $\begin{array}{l}\text { amatus fueram } \\
\text { ('habia sido amado') }\end{array}$ \\
\hline
\end{tabular}

Figura I. Generalización de la pasiva perifrástica

Esta es la situación que encontramos en castellano medieval y que llega a nuestros días:

(22) pues que esto assi es fecho. prendet del auer dela tierra por present (Fazienda de Ultramar, 1200)

En esta manera fue poblada la uilla de Caliz e la ysla ... e fue much amado en toda Espanna. (Cronica General de Espanna, 1270)

Mas en el dia biernes en la cort de los alcaldes ninguna otra cosa no.y sea fecha si non dar los judicios (Fuero de Teruel, 1300)

3.2.1.4. Auxiliar de verbos intransitivos y pronominales

En latín, la voz activa de los verbos (y, por lo tanto, de los verbos transitivos) acabó expresando los tiempos del perfectum (acción terminada) mediante perífrasis con HABERE ( $=$ 'tener'), que fueron reanalizadas como formas compuestas del verbo:

(23) librum scriptum habeo ('tengo un libro escrito') > habeo scriptum librum ('he escrito un libro')

Los verbos en voz media y los verbos deponentes formaban los tiempos del infectum con desinencias iguales a las de la pasiva, y los del perfectum mediante perífrasis con el verbo ESSE. Estos verbos pasaron a conjugar los tiempos del infectum como los de la voz activa, pero conservaron el uso de perífrasis con ESSE para los tiempos del perfectum. Con ello, se generalizó el uso de una construcción perifrástica para formar los tiempos del perfectum: con HABEO los verbos transitivos, y con sum los antiguos verbos deponentes, medios e intransitivos:

\begin{tabular}{|l|l|}
\hline infectum & perfectum \\
\hline scribo & scripsi \\
\hline nascor & natus sum \\
\hline moveor & motus sum \\
\hline iacio & iactus sum \\
\hline
\end{tabular}

\begin{tabular}{|l|l|}
\hline infectum & perfectum \\
\hline scribo & scriptum habeo \\
\hline nasco & natus sum \\
\hline (me) moveo & motus sum \\
\hline (me) iacio & iactus sum \\
\hline
\end{tabular}

Figura II. Formación de los tiempos compuestos de perfectum 
Situación que pervive en el castellano medieval, ${ }^{3}$ donde los verbos intransitivos que indican cambio de estado o de situación, así como las construcciones pronominales, forman los tiempos de perfecto con el verbo ser, entendido como auxiliar:

(24) e fue se por su tierra don era sallido (1180) que les anda por las uenas, e que se es apoderada la calentura en ellos (1250) Pues que la batalla fue acabada desauenturadamientre et fueron todos muertos los unos et los otros... (Cronica General de Espanna, 1270)

Dixo esto la cuytada, a sus pies se es echada (1270)

en tal manera que son idos e se van a morar fuera del mio señorio (1315)

en çierto creed que en mal punto fue nascido el omne que quiso ualer mas por las obras de su linage que por las suyas (Libro de los estados, 1327)

los de Cordoua, que eran ydos enla delantera ... quando sopieron quel jnfante don Pedro era muerto, tan grand desmayamiento tomaron que fuxieron todos... (1344)

\subsubsection{Valor locativo}

A menudo encontramos usos medievales del verbo ser que derivan directamente de ESSE latino, con valor de locativo ('estar en un lugar'):

(25) Vinieron a Jacob so padre que era en Ebron en tierra de Canaan. (Fazienda de Ultramar, 1200)

del abbad nin delos monges de san Fagund por o quier que sean. (1222)

...uendemos a uos Ferrando... las casas e las tiendas e los huertos e la nuestra uinna de Tafaia... las quales son cerca de Sancta Maria la Redonda en Logronno (1228)

et todos los caualleros et las compannas que eran y con ell ouieron end usgo (Cronica General de Espanna, 1270)

con la merçed de Dios luego sere en Valençia con vusco... si esto me otorgades luego sere con vusco (Carta, 1332)

e que fallara muchos despues de mi muerte que seran contra ella. ... E desque fuemos todos estos conel rey (Libro de las Armas, 1342).

Pero con este valor se dan, desde antiguo, alternancias con el verbo estar ( $<$ lat. STARE, 'estar de pie'), con cierta preferencia por ser para expresar situación permanente, y de estar para la situación circunstancial, pero con una tendencia progresiva a preferir estar como locativo a partir del siglo xIV:

(26) Pareşia que estauan tan baxos que passaua el rio de Tajo por çima dellos. E desque fueron en cabo del escalera fallaron una posada muy buena e una camara do estauan los libros (Conde Lucanor, 1330-35)

Estando en Tiscar este jnfante don Pedro, llegol mandado en commo el infante don Joan, que estaua en Baena, que queria entrar a la Vega de Granada. e commo quier que consejauan al jnfante don Pedro quantos con el eran que fuesse çercar a Uelma ... E toda la gente dela caualleria que estauan con el non lo sopieron sinon muy pocos... los de Cordoua, que estauan a media legua dellos atendiendo que llegassen los jnfantes

3 Y que se conserva hasta la actualidad en otras lenguas románicas (cf. francés je suis allé, ils se sont endormis o italiano sono andato). 
don Johan e don Pedro e enbiaron lo luego dezir ala jnfante donna Maria su muger que era en Cordoua e que estaua en dias de encaesçer... E quando don Joan, fijo del jnfante don Joan, que estaua en Baena, sopo en commo su padre era muerto e quel non trayan sus vassallos, tomo ende muy grand pessar (Crónica de Alfonso XI, 1344)

Estando el Rey don Pedro en Seuilla, martes veynte e nueve dias de mayo deste dicho anno, llego alli don Fadrique su hermano, maestre de Santiago, e venia de cobrar la villa e castillo de Jumilla, que es enel reyno de Murçia (Crónica del Rey don Pedro, 1385)

\subsubsection{Valor resultativo}

También aquí son numerosos los ejemplos medievales que reflejan el uso resultativo del verbo ser:

(27) La primera es por que los fijos delos jnfantes non son tan bien criados commo les cumple ca los que los crian por les fazer plazer trabajan enlos falagar ... et en esto son engañados (Libro de los Estados, 1327)

Dixo me commo, loado a Dios, sodes ya bjen sano ... E set seguro que vos et todos vuestros caçadores de aues e de canes vos seredes en roydo con el recabdo que yo vos leuare (Carta, 1332)

E quando llego al real era ya el rey de Castilla aposentado que lo salio a resçebir con muy grand alegria (Crónica de 1344)

La terçera razon es que siruades a la reyna doña Maria ca so çierto que lo aura muy grant mester (Libro de las Armas, 1342)

Mas ya tanto era enamorada de Esmere que tenia que non auja mejor quel enel sieglo (Cuento del emperador Otas de Roma, h. 1370)

Pero son frecuentes las alternancias con estar, sobre todo a partir del siglo XIV:

(28) Non deuemos estar çiertos nin seguros de muerte (Libro de Buen Amor, 1330-43)

\subsection{Ser y estar en el español moderno y contemporáneo}

El español contemporáneo conserva algunos de estos usos medievales de ser, pero ha procedido a una especialización de valores:

\subsubsection{Valor existencial}

Es, probablemente, el único valor que se mantiene inalterado respecto de su antecesor latino y medieval:

(29) Ser o no ser...

Son las cuatro.

Que fue en Granada el crimen...

\subsubsection{Valor copulativo}

Como verbo copulativo, se ha producido una especialización de usos entre los verbos ser y estar: 
- Con adjetivo calificativo, ser atribuye cualidades esenciales del sujeto, mientras que estar le atribuye cualidades accidentales, resultantes del devenir:

(30) el cielo es azul / el cielo está azul;

- Con nombres, pronombres y adjetivos determinativos, se ha impuesto el uso exclusivo de ser:

(31) Juan es escritor;

el autor fue él;

el mejor libro es este;

los que asistieron fueron siete.

- En cambio con adverbios (o expresiones adverbiales) y gerundios, se ha especializado el uso de estar, en paralelo con los valores resultativos:

(32) la función estuvo muy bien;

el queso estaba en mal estado;

el chico estaba jugando;

\subsubsection{Valor locativo}

Con este valor, se ha especializado el uso del verbo estar

(33) el diccionario está en la biblioteca.

\subsubsection{Construcciones de pasiva}

Se ha generalizado el uso de ser como auxiliar de la pasiva perifrástica. Pero, junto a ella, se ha ido imponiendo progresivamente una nueva construcción de pasiva, presente ya en textos medievales, y que refleja cierta influencia de la sintaxis árabe, donde se distingue claramente entre una pasiva agentiva y una pasiva no agentiva. El castellano medieval recurrió a las construcciones con el pronombre reflexivo se para expresar estos valores de pasiva en que no se hace mención expresa del agente:

(34) segunt el fuero d'aqueill logar do se fizo el homicidio (1250) E la razon por que se fizo aquello començosse en la manera que oyredes (1293) sy contesçio e fue fecho por occasion o sy se fizo por crueldat de maldat adrede (1293) por contar de las cortes que se hizieron en la çibdad de Palençia (1348-79)

El español contemporáneo muestra una restricción progresiva del uso de la pasiva perifrástica frente a una generalización de la pasiva refleja para usos no agentivos:

(35) fue inaugurada la exposición / se inauguró la exposición. * son reunidas las juntas / se han reunido las juntas.

*son vendidos coches usados / se venden coches usados. 


\subsubsection{Valor resultativo}

Finalmente, para los valores resultativos se ha impuesto el uso exclusivo de estar:

(36) estoy cansada;

la puerta está abierta;

estaba tan enamorada...

\section{Los clíticos}

\subsection{Pervivencia de la flexión de caso}

Las formas de pronombre personal son las únicas que, tras la crisis de flexión de casos en el sistema nominal del latín, han conservado hasta nuestros días un resto de la antigua flexión, acompañado de la aparación de un nuevo valor en las lenguas románicas: los clíticos pronominales.

Los pronombres de primera y segunda persona muestran, ya en latín tardío, un uso indistinto para los valores de objeto directo e indirecto (acusativo y dativo), con la generalización de lo que había sido la forma de acusativo para ambas funciones. El pronombre de tercera persona, en cambio, presenta tres formas posibles que podemos esquematizar según el cuadro siguiente:

\begin{tabular}{|l|l|}
\hline & latín \\
\hline nom. & ille illa illud \\
\hline acus. & illum illam \\
\hline dat. & illi \\
\hline
\end{tabular}$\rightarrow \rightarrow$\begin{tabular}{|l|l|}
\hline castellano primitivo \\
\hline ell(e) ella ello \\
\hline elo ela \\
\hline ele $(\mathrm{ge})$ \\
\hline
\end{tabular}$\rightarrow$\begin{tabular}{|l|}
\hline español moderno \\
\hline él ella ello \\
\hline lo la \\
\hline le $(\mathrm{se})$ \\
\hline
\end{tabular}

Figura III. Variación de caso en los pronombres pesonales

Sin embargo, mientras la distinción entre la función de sujeto y la de complemento es estable, acentuada por el carácter tónico del primero frente al átono del segundo, el valor de clítico de las formas derivadas del acusativo y del dativo muestra, desde antiguo, una clara tendencia a la inestabilidad.

\subsection{Leísmo, laísmo y loísmo}

En la alternancia de las formas derivadas del pronombre latino en función complementaria confluyen varios factores, que resumimos a continuación.

4 Obsérvese que la forma primitiva de masculino elle sufrió apócope de la [-e] átona final, con lo que quedó un sonido palatal en posición final de palabra, situación fónica rechazada sistemáticamente por el castellano, por lo que el sonido palatal [ $\bullet$ ] fue sustituido por el correspondiente de la articulación alveolar [1]. 


\subsubsection{Relación con el "neutro de materia"}

Las alternancias entre los clíticos lo/le parecen reflejar, en ocasiones, la pervivencia de una antigua distinción de los romances del área cántabra, que establece una diferenciación entre los nombres de contenido genérico y los de contenido específico o determinado, distinción que, en última instancia, se relaciona con el llamado "neutro de materia" (Echenique, 1981), con preferencia por lo como sustituto de un nombre de materia, y de le como sustituto de un nombre determinado:

(37) tomaba estambre de unas casas, dávalo a hilar en otras (Celestina) - ¿Cómo faltó el paño de manos? - A tu rufián le avrás dado (Celestina)

\subsubsection{Rasgos semánticos del sintagma verbal}

Asimismo, determinados rasgos semánticos del sintagma verbal (dinamicidad del verbo, aspecto verbal perfectivo o imperfectivo, grado de agentividad del sujeto) condicionan la preferencia por una u otra de estas formas (Flores, 2006). Así:

a) Un verbo cuyo contenido semántico implique el rasgo [+dinámico] condicionaría la preferencia por $l o$, mientras que el rasgo [-dinámico] se asocia con la preferencia por $l e$ :

(38) Priso lo el conde, pora su tierra lo leuaua (Cid); lo colgaron; lo tomaron; Si ellos le viessen non escapara de muert (Cid); le amauan; le tenia por señor;

b) Un verbo usado en un tiempo que implique un aspecto perfectivo parece condicionar la preferencia por $l o$, mientras que el aspecto imperfectivo se asocia con la preferencia por $l e$ :

(39) lo llevaron delante del gobernador; lo llamó;

lo mataron...

frente a:

(40) vio que le llamaba; hasta que le matassen; pidió que le llevassen...

c) El mayor o menor grado de agentividad del sujeto (y, por lo tanto, en relación con el rasgo $[ \pm$ persona] del sujeto) puede también condicionar la preferencia por lo o por le:

(41) e servir lo he siempre;

et tomo los priuado e subio los suso el muro;

y yo los satisfice;

pero:

(42) sirvan le sus heredades;

con el grant desmejoramiento que les tomo;

e como la tierra para poblar no les satisficiesse; 


\subsubsection{Carácter aislado de la distinción casual}

Por otra parte, el carácter aislado de la distinción casual dentro del sistema del español, donde las únicas distinciones en el ámbito nominal y pronominal son las de género y número, llevan a los hablantes a establecer, también en los clíticos, una distinción genérica, paralela a la que se da en otras formas pronominales como son los demostrativos. Relación analógica que se ve favorecida por el desarrollo del uso de la preposición $a$ ante el complemento directo de persona, con lo que la estructura superficial del acusativo de persona coincide con la del dativo: $a+\mathrm{SN}$.

Esquemáticamente:

\begin{tabular}{|c|c|c|c|c|c|c|c|}
\hline & masc. & $\mathrm{fem}$ & neut. & \multirow{3}{*}{$\leftrightarrow$} & masc. & $\mathrm{fem}$ & neut \\
\hline sing. & este & esta & \multirow{2}{*}{ esto } & & le & la & \multirow{2}{*}{10} \\
\hline plur. & estos & estas & & & los & las & \\
\hline
\end{tabular}

Figura IV. Relación analógica entre personales y demostrativos

Esta situación es la que encontramos en autores castellanos de los Siglos de Oro:

(43) Mirabanle las mozas, y andaban con los ojos buscandole el rostro, que la mala visera le encubria; mas como se oyeron llamar doncellas, cosa tan fuera de su profession, no pudieron tener la risa, y fue de manera, que Don Quixote vino ... à decirlas: Bien parece la mesura en las fermosas; ... pero non vos lo digo porque os acuitedes... Miròle el Ventero, y no le pareciò tan bueno como Don Quixote decia; ... y acomodandole en la cavalleriza, bolviò à ver lo que su huesped mandaba, al qual estaban desarmando las doncellas ... las quales, aunque le avian quitado el peto, y el espaldar, jamàs supieron, ni pudieron desencaxarle la gola, ni quitarle la contrahecha celada. (Quixote, 1605). La razon tiene fuerça en el hombre de formarla a su beneplacito. Si dieramos caso que los que le criassen, o fuessen mudos, o no le hablassen ninguna palabra, formaria el su lenguage propio. (Covarrubias, Tesoro, 1611).

Quando v.e. lo dejare que se halle con lo que conuiene, i no gastarlo todo en hazer seruizios a quien ni los quiere ni se los dejan conozer. ... No lo e dicho tan claro pero dejase entender $i$ en esto reseruo mucho $i$ siempre lo e hecho asi... El embajador de Benezia dijo que ... me mandasen escribir ese papel que ba con esta, que le firmase i se bio y leyo $i$ no se fiaron de mi $i$ bieron mi carta $i$ me la hizieron cerrar delante dellos $i$ io despues la torne a abrir $i$ abise al pie a v.e. desto... Pues ... el dia que el embajador dio esta queja desta rebelion o conjura pidio el mismo que luego al punto se quitase de alli a don Alonso. $i$ luego al punto le quitaron... alo hecho el $P$. Rmo. ... pero el hecho de mudarle porque lo pidieran ... a escandalizado el mundo todo. (Quevedo, Carta, 1618).

En algunas gramáticas del siglo xvir, como la de Gonzalo Correas, se describe claramente esta situación y se propone un esquema similar al anunciado en líneas anteriores, con mención explícita de la desaparición de la distinción casual entre dativo y acusativo, con la única excepción del masculino plural, donde son posibles dos formas: los, tanto para acusativo como para dativo, y les, que puede aparecer como dativo en alternancia con los: 
(44) Para los ultimos é dexado estos articulos pospositivos, rrelativos, encliticos, fixados $i$ asidos: le, les, los, la, las, lo, porque ai mucho que dezir dello, $i$ que advertir el abuso que ai en usar algunos dellos confusamente... Digo que le es masculino, i tiene dos plurales, les para dativo solamente, $i$ los para acusativo las mas vezes, $i$ algunas para dativo. La, las es femenino; lo es neutro. I rrefieren todos antezedente de terzera persona, $i$ ellos an de estar en dativo, o acusativo... Demos exenplos de lo dicho con verbos: vamosle a buscar, dirasle que venga, mostrareles la casa i direlos que se vaian; acobosela a Maria la pazienzia (Arte Kastellana, 1627).

Es decir:

\begin{tabular}{|l|c|c|c|}
\cline { 2 - 4 } \multicolumn{1}{c|}{} & masculino & femenino & neutro \\
\hline singular & le & la & 1o \\
\hline plural & $\begin{array}{l}\text { los (ac. } y \text { dat. }) \\
\text { les (solo dat. })\end{array}$ & las & \\
\hline
\end{tabular}

Figura V. Los clíticos pronominales en las gramáticas del siglo XVII

Sin embargo, esta situación, general en las zonas del castellano viejo, no es la más habitual en otras áreas del español, como ocurre en el español meridional y en Hispanoamérica, donde generalmente se conserva inalterada la distinción casual. A partir del s. XVIII la Academia intenta restablecer la distinción casual, pero acaba admitiendo el uso de le para el acusativo singular de persona, de acuerdo con el esquema:

\begin{tabular}{|l|l|c|c|c|}
\cline { 3 - 4 } \multicolumn{2}{c|}{} & masculino & femenino & neutro \\
\hline \multirow{2}{*}{ singular } & acusativo & lo $/(\mathrm{le})$ & \multirow{2}{*}{ la } \\
\cline { 2 - 4 } & dativo & \multicolumn{2}{|c|}{ le } \\
\hline \multirow{2}{*}{ plural } & acusativo & los & las \\
\cline { 2 - 4 } & dativo & \multicolumn{2}{|c|}{ les } \\
\hline
\end{tabular}

Figura VI. Los clíticos pronominales en la gramática académica

(45) Tu padre no era feliz. ... Nunca le vi alegre (Filomeno a mi pesar, 1988) A Pedro nunca le conté que lo habia visto en aquella situación. Al despedirlos les di veinte pesos (Crimenes, 1979)

Con todo, la situación dista mucho de ser homogénea. Y las características semánticas del sintagma verbal, a las que aludía en párrafos precedentes, condicionan sustancialmente estos usos ${ }^{5}$.

5 Puede verse un interesante y esclarecedor resumen de estas cuestiones en el Diccionario Panhispánico de Dudas de la RAE, consultable a través de internet: http://buscon.rae.es/dpdI/ (buscar leismo). 


\section{Las preposiciones por y para}

\subsection{Origen común y usos medievales}

En sus orígenes, las antiguas preposiciones latinas PER, PRO y PROPTER, confluyeron en castellano en una forma única, por, que recogía los valores de todas ellas:

(46) e fue se por su tierra don era sallido (1180)

$e$ desto nascen grandes contiendas e muchos otros males por las tierras. por que conuiene a los reyes que an a tener e a guardar sus pueblos en paz e en justicia, que fagan leyes e posturas e fueros por que el desacuerdo que an los omnes naturalmientre entressi se acuerde por fuerça de derecho... Onde nos por toller todos estos males que dicho auemos fiziemos estas leyes... (Siete Partidas, 1250)

e otro preuillejo del rey nuestro padre en como por fazer bien e merçed al conçejo de Seuilla (1284)

En ocasiones, cuando se pretende insistir sobre la direccionalidad de la preposición por, esta se intensifica con la presencia conjunta de la preposición $a$, creando así una forma compleja (por a) cuyos componentes acaban fusionándose $\mathrm{y}$, por asimilación, dan lugar a una nueva preposición, para, especializada en la expresión de los valores de dirección:

(47) Esto la niña dixo e tornós pora su casa. (Mio Cid, 1140) Acoytadvos e yd pora mio padre e dezidle qual merced me a Dios fecha (Fazienda de Ultramar, 1200)

que vos vengades luego para el e que traygades convusco la cuenta (1300).

o de finalidad:

(48) e en uostro senorio sean entradas, pora uender e pora enpenar, e pora dar e pora fazer toda aquela cosa (1129)

demandemos sus fijas pora con ellas casar (Mio Cid, 1140)

njn de cortar arboles que son pora leuar fructo o pora madera. (1196)

la çevera de la tierra que podra aver e guardela pora los .vij. annos de la fambre (Fazienda de Ultramar, 1200)

Et el jurado e el meryno buscaron le para lo prender (Fuero de Burgos, 1290)

en manera que los ayades bien parados para mio seruiçio (1300)

Aunque, en aquellos contextos en los que el hablante no percibe la necesidad de destacar el valor direccional o de destino, sigue siendo posible la presencia de la preposición por, sin el incremento prepositivo:

(49) Mas fazenlo por tener libertad de poder fazer lo que quieren (1300-05) Et enuio hi de sus barones por tener las senyorias de aquellas tierras (1396) El entro en canpo e fizo batalla por mantener la fe de aquel papa e fue vençido (1440) 


\subsection{Diferenciación y confluencia de usos en el español moderno y contemporáneo}

Esta situación se mantiene parcialmente en español contemporáneo, donde es todavía posible el uso de por con valor final cuando la idea de finalidad va asociada a la de la causa, sin que ello dé lugar a interpretaciones erróneas, porque el contexto es suficiente para deshacer posibles ambigüedades (o cuando la posible ambigüedad no modifica el contenido del mensaje):

(50) se levantó a las seis por no llegar tarde. dar la vida por la patria. brindo por el éxito de la empresa.

En cambio, la finalidad "pura" se expresa preferentemente con la preposición para:

(51) se fue para quedarse, como aqui se quedò para irse (Quevedo, 1625)

Asimismo, cuando la preposición por se asocia a la conjunción que para formar una locución conjuntiva, puede conservar el valor de finalidad. En este caso, la norma gráfica obliga al uso de los dos términos separados cuando funcionan con valor final, frente a la unión gráfica para el valor causal. Destaquemos, sin embargo, que en cualquier caso, la distinción semántica queda claramente reflejada (y, por lo tanto, también en la oralidad) por la estructura sintáctica, con verbo en subjuntivo para el valor final y verbo en indicativo para el valor causal:

(52) se lo dije por que viniera antes vs. se lo dije porque vino antes.

Con valor de dirección (= 'hacia'), en cambio, ya solo es posible para, mientras que por expresa valores relacionados con la idea de tránsito ( $=$ 'a través de'). En este caso, la preposición es el único elemento de la frase que permite deshacer posibles ambigüedades, y de ahí su obligatoriedad:

(53) y assi se fue para don Quixote, los braços abiertos, diziéndole (Quixote, 1605) tomando su ordinario vestido de pastor, se fue por la ribera del Iler (1787)

sin ser parte a animarla nuestros gritos, se fue por el resbaladero cuesta abajo (1882)

\section{Consideraciones finales}

Decía al principio que el conocimiento de cómo se ha llegado a la situación actual puede permitir explicar de forma más coherente algunas aparentes "anomalías" del español actual. El objetivo de esta panorámica histórica era, pues, proporcionar a nuestros profesores de español como lengua extranjera algunas herramientas útiles para su quehacer cotidiano. Espero haberlo conseguido. 


\section{Referencias bibliográficas}

Cano, Rafael (coord.) (2004): Historia de la lengua española, Barcelona, Ariel.

Company Company, Concepción (dir.) (2006): Sintaxis histórica de la lengua española, México, FCE.

Correas, Gonzalo (1627): Arte Kastellana, edición de M. Taboada Cid, Santiago, Universidad de Santiago de Compostela, 1984.

Echenique Elizondo, $\mathrm{M}^{\mathrm{a}}$ Teresa (1981): «El sistema referencial en español antiguo: leísmo, laísmo y loísmo». Revista de Filología Española, 61, 113-157.

Girón Alconchel, José Luis (2004): «Cambios gramaticales en los Siglos de Oro», en R. Cano (coord.) Historia de la lengua española, Barcelona, Ariel, 859-893.

Flores Cervantes, Marcela (2006): «Leísmo, laísmo y loísmo», en Company, Concepción (dir.) (2006): Sintaxis histórica de la lengua española, México, FCE. 671-749.

Lleal Galceran, Coloma (1990): La formación de las lenguas romances peninsulares, Barcelona, Barcanova.

Moliner, María (1970): Diccionario de uso del español, Madrid, Gredos.

Penny, Ralph (2004): «Cambios morfosintácticos en la Baja Edad Media», en R. Cano (coord.) Historia de la lengua española, Barcelona, Ariel, 613-656.

Real Academia Española (2006): Diccionario Panhispánico de Dudas, Madrid, RAE.

Real Academia Española: Corpus diacrónico del español (CORDE).

Rini, Joel (1992): Motives for Linguistic Change in the Formation of the Spanish Object Pronouns, Newark, Juan de la Cuesta. 